\section{TP Periodica Polytechnica Civil Engineering}

OnlineFirst (2018) paper 11554

https://doi.org/10.3311/PPci.11554

Creative Commons Attribution (i)

\title{
Shear Buckling of Plate Girders with Corrugated Web Restrained by End Stiffeners
}

\author{
Witold Basiński ${ }^{*}$
}

RESEARCH ARTICLE

Received 04 October 2017; Revised 08 January 2018; Accepted 20 February 2018

\begin{abstract}
The study reports the investigations into the effect produced by flexural stiffness of end stiffeners on the design buckling resistance of the sine wave webs of girders. Experimental investigations were concerned with load displacement paths in sinusoidally corrugated web girders, composed of structural items and made to the full scale. The phenomena occurring in experimental investigations were represented using the Finite Element Method. In numerical models based on FEM analysis, the same failure modes of webs that were found in experimental investigations into corrugated web girders were accounted for. FEM numerical analysis was performed for girder models with webs 500, 1000, 1250 and $1500 \mathrm{~mm}$ in height, made of corrugated sheet metal 2, 2.5 and $3 \mathrm{~mm}$ in thickness. On the basis of laboratory tests and FEM analysis, a new method for estimating design shear buckling resistance for girders with semirigid and rigid end stiffeners was proposed. The method relies on the determination of interactive buckling resistance. The solution presented in this study was compared with formulas currently used for buckling resistance estimation. It was shown that the use of girder rigid end stiffeners produces in increase in shear buckling resistance up to $11 \%$. Conclusions were drawn and recommendations were made with respect to the sizing of sine wave corrugated web girders with semirigid and rigid end stiffeners.
\end{abstract}

\section{Keywords}

sine wave corrugated web girders, interactive shear buckling resistance, design shear buckling resistance, semirigid end stiffener, rigid end stiffener, finite element

\footnotetext{
1 Faculty of Civil Engineering, Silesian University of Technology Akademicka 5, 44-100 Gliwice, Poland

*Corresponding author, email: witold.basinski@polsl.pl
}

\section{Introduction}

Corrugated metal sheet was patented in the United Kingdom in 1829 by a British architect and engineer Henry Palmer. An idea of using corrugated metal sheet for webs of plate girders emerged as early as in the 1930s. It was observed that sheet folds perpendicular to flanges produced web stiffening, which significantly increased critical stress, thus allowing the use of slender walls. Starting from the 1960s, the fabrication of plate girders with web folds located parallel to beam axes was considered. Such an orientation of the web folds, however, made it necessary to for transverse stiffeners to be welded into each site a concentrated load occurred. This disadvantage was not found in plate girders with webs, the folds of which were perpendicular to the flanges. As appropriate welding technologies were not available then, girders of that type did not become widely used. Fabrication automation in the late 1980s/early 1990s made large-scale use of such girders possible. Currently, corrugated web I-girders are most commonly employed in the load carrying structures of single- or two-bay buildings. The girders available on the market have webs that are 2.0, 2.5 and $3.0 \mathrm{~mm}$ in thickness and vary from 333 to $1500 \mathrm{~mm}$ in height. The mill-guaranteed yield strength of corrugated web steel is $f y=215 \mathrm{MPa}$.

In sine wave corrugated web girders used in civil engineering, the mechanism of corrugated web buckling due to the action of shear load is still classified separately as local and global instability [1]. As regards local instability, the corrugated web acts as a group of mutually connected flat panels that are restrained by flanges. As for global instability, a group of waves buckles along the diagonal, which results in the web adopting a classic arc shape. In girders with trapezoidal web profile utilised in bridge structures, the buckling mechanism in the corrugated web was split into two categories classified separately until as late as the mid-1990s. Then, it was observed [2] that the local instability initiated in one of the folds turns into the failure of neighbouring folds. This failure mode was first classified as local instability [2, 3]. Only in the following years, the failure mode of trapezoidally corrugated webs that showed the features of both local and global 
instability began to be classified as an interactive mode of instability [2, 3, 4, 5, 6, 7]. Based on numerous investigations, many models were developed to estimate interactive shear buckling resistance $[4,5,8,9,10,11]$. The models relied mainly on mutual interaction between stresses in the web of local and global instability and shear yield strength. On the basis of the models, formulas for estimating design shear buckling resistance were devised [4, 5, 6, 12]. The formulas, however, did not account for sine wave folds of corrugated webs. In 2009, Eldib [13] put forward a solution for girders with sinusoidal web profile that were used in bridge structures. The solution was based on relating the slenderness to the buckling stress obtained from FEM investigations.

The papers by the author of this study $[14,15,16]$ reported observations that design shear buckling resistance in sine wave corrugated webs given in the standard [1] is overestimated. Additionally, investigations indicated that in girders with sinusoidal web profile, an interaction occurs between local and global mode of shear instability, which reduces buckling resistance of girders. It was observed that for the end-plate connection of prefabricated elements of girders, the zone of shear instability of the web shifted from the connection towards the stiffener. Also, the analysis of shear resistance and investigations into corrugated and flat web girders constructed of items showed a considerable impact of end stiffeners on the buckling resistance of the web. In the flat web, the effect of end stiffeners on shear buckling resistance already manifests itself at slenderness of $\lambda$ (buckling length/radius of gyration) $>1.08$ [17]. As regards sine wave corrugated web girders, the range of slenderness is $1.88<\lambda\left(l_{w} / i_{y}\right)<7.98$. In corrugated web girders, end stiffeners are usually made of flat plates.

This study presents the investigations into the effect of flexural stiffness of end stiffeners on the web interactive and design buckling resistance in sine wave corrugated web girders.

To that end, load-displacements paths (LDPs) for two groups of simply supported sine wave corrugated web girders were examined. The girders, fabricated of items, were made to the full scale. Girders were designed in accordance with standards and recommendations $[1,18]$.

The phenomena occurring in the experimental investigations [19] were represented using the Finite Element Method. It was shown how FEM analysis was used to numerically estimate the design buckling resistance of corrugated web of girders with semirigid and rigid end stiffeners. In numerical models, the same failure modes of the corrugated web were found as in the experimental investigations of SIN girders. FEM numerical analysis of the buckling resistance of girders was performed using models with the web height of 500, 1000,1250 and $1500 \mathrm{~mm}$, made of corrugated sheet metal 2, 2.5 and $3 \mathrm{~mm}$ in thickness. A new method for the estimation of design shear buckling resistance of corrugated web girders with semirigid and rigid end stiffeners was developed. The method is based on the determination of the interactive buckling resistance, which represents the experimental results in a better way.

\section{The shear buckling resistance of the sine wave corrugated web girders}

Many researchers were concerned with the behaviour of corrugated web girders. Exemplary solutions [20, 21, 22] based on equilibrium equations for an orthotropic plate allowed the estimation of shear buckling resistance at the local and global instability.

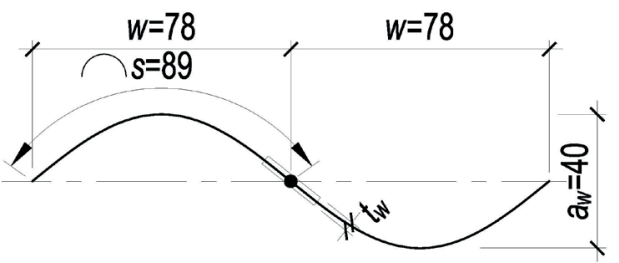

Fig. 1 Sine wave of the girder web

Local instability occurs when the ratio of the length of the sine wave fold to the fold thickness is too high (Fig. 1). Equation (1) $[1,23]$ describing shear buckling resistance is based on the classical flat plate buckling theory:

$$
\tau_{c r L}=k_{L} \frac{\pi^{2} E}{12\left(1-v^{2}\right)}\left[\frac{t_{w}}{s}\right]^{2},
$$

in which $E=210 \mathrm{GPa}$ - modulus of elasticity, $v$ - Poisson's ratio. Additionally, modified buckling coefficient $k_{L}$ :

$$
k_{L}=\left(5.34+\frac{a_{w} \cdot s}{h_{w} t_{w}}\right),
$$

was made dependent on: $s=89 \mathrm{~mm}$ - length of the arc of half-sine wave; $a_{w}=40 \mathrm{~mm}$ - height of the two half-sine waves, $h_{w}, t_{w}-$ web height and thickness.

In shear, global instability is characterised by buckling of the web waves along the diagonal produced by the tension field. The phenomenon occurs when the ratio of the web height $h_{w}$ to the sine wave length of the fold, or its thickness $t_{w}$ is too high (Fig. 1). Equation (3) [1] describing buckling stress was based on the stiffness relations of the orthotropic plate [10] which substituted the corrugated web:

$$
\tau_{c r G}=k_{G} \frac{\left(D_{y} D_{z}^{3}\right)^{1 / 4}}{t_{w} h_{w}^{2}},
$$

where: $D_{y}$ - orthotropic plate bending stiffness in a plane perpendicular to generatrix of the web shell; $D_{z}$ - orthotropic plate bending stiffness in a plane parallel to generatrix of the web shell.

In this case, a constant value of 32.4 was assigned to the buckling coefficient $k_{G}$. The available solution, however, does not account for the interaction between local and global modes of instability. 
In [13] Eldib analysed behaviour of corrugated web girders with a wavy web profile. He demonstrated the advantageous effect of the web corrugation on an increase in the buckling resistance value. Eldib proposed also a solution concerning interactive buckling resistance of the wavy web that corresponded to the trapezoidal geometry, which was based on analysis of regression obtained from FEM investigations. The solution adopted by Eldib [13] indicates that interactive buckling resistance of the corrugated web could be even a few times higher than that of the corresponding trapezoidal web at $h_{w} / t_{w}=$ 300. The difference in the buckling resistance magnitude fades away quickly as the $h_{w} / t_{w}$ ratio increases.

Experimental investigations carried out by the author, described in study [19], indicated that at $a>h_{w}$, shear buckling resistance of the corrugated web depends mainly on the web height $h_{w}$. Additionally, mutual interaction between local and global web instability was found to occur. That lowered the shear buckling resistance of corrugated web girders compared with the values reported in the literature $[1,18]$. Interaction is closely related to the use of girder end stiffeners.

\section{Design shear buckling resistance of corrugated web girders}

For corrugated web girders that utilise trapezoidal web profile, the general form of the equation describing interactive buckling resistance $\tau_{c r I}$ was expressed as the following relation:

$$
\begin{gathered}
\left(\frac{1}{\tau_{c r I}}\right)^{n}=\left(\frac{1}{\tau_{c r L}}\right)^{n}+\left(\frac{1}{\tau_{c r G}}\right)^{n}, \\
\left(\frac{1}{\tau_{c r I}}\right)^{n}=\left(\frac{1}{\tau_{c r L}}\right)^{n}+\left(\frac{1}{\tau_{c r G}}\right)^{n}+\left(\frac{1}{\tau_{y}}\right)^{n},
\end{gathered}
$$

where: $n=1$ [Driver (4)], $n=2$ [Abbas (8)], $n=4$ [Hiroshi (11)] in Eq. (4) and $n=2$ [EL-Metwally (9)], $n=3$ [SayedAhmed (5)] in Eq. (5).

Equations (4) and (5) were based on mutual stress relations at the web local $\tau_{c r L}$ and global instability $\tau_{c r G}$, and the shear yield strength $\tau_{y}$. Equations (4) and (5) provided a basis for devising formulas necessary to estimate design shear buckling resistance $[4,5,6,12]$.

The solution (8) proposed by Moon [12] in 2009 relies on interactive buckling resistance $\mathrm{Yi}$ [7]. In order to determine shear buckling resistance $\tau_{n, M}$, it is necessary to estimate slenderness $\lambda_{s}(6)$ that depends on the interactive buckling coefficient $k_{I}(7)$. Coefficient $k_{I}$ incorporates the values of coefficients at local $k_{L}$ and global instability $k_{G}$. In this solution, it is not necessary to separately compute stresses at local and global instability.

$$
\lambda_{s}=1.05 \sqrt{\frac{\tau_{y}}{k_{I} E}}\left(\frac{h_{w}}{t_{w}}\right),
$$

$$
\begin{gathered}
k_{I}=\frac{30.54}{5.34\left(h_{r} / t_{w}\right)^{-1.5}+5.72\left(w / h_{w}\right)^{-1.5}}, \\
\frac{\tau_{n, M}}{\tau_{y}}= \begin{cases}1.0 & \text { for } \lambda_{s} \leq 0.6 \\
1-0.614\left(\lambda_{s}-0.6\right) & \text { for } 0.6<\lambda_{s} \leq \sqrt{2}, \\
1 / \lambda_{s}^{2} & \text { for } \sqrt{2}<\lambda_{s}\end{cases}
\end{gathered}
$$

In 2011, Sause and Braxtan [6] proposed that design shear buckling resistance should be determined on the basis of Eq. (9):

$$
\tau_{n, S B}=\tau_{y}\left(\frac{1}{\lambda_{I, 3}^{6}+2}\right)^{1 / 3}
$$

Equation (9) was based on interactive slenderness computed in accordance with (10) for the parameter value of $n=3$. Local and global slenderness was determined from relations (11) and (12):

$$
\begin{gathered}
\lambda_{I, n}=\lambda_{L} \lambda_{G}\left(\left(\frac{1}{\lambda_{L}}\right)^{2 n}+\left(\frac{1}{\lambda_{G}}\right)^{2 n}\right)^{1 / 2 n}, \\
\lambda_{L}=\sqrt{\frac{12\left(1-v^{2}\right) \tau_{y}}{k_{L} \pi^{2} E} \frac{w}{t_{w}}} \\
\lambda_{G}=\sqrt{\frac{12 h_{w}^{2} \tau_{y}}{k_{G} F(\alpha, \beta) E t_{w}^{0.5} b^{1.5}}}
\end{gathered}
$$

For global instability, coefficient $k_{G}$ was based on the proposal put forward by Esley [21]. The coefficient ranged from 36 to 68.4 . In addition, coefficient $F(\alpha, \beta)$ was made dependent on the web corrugation geometry. This coefficient was determined from Eq. (13) [9].

$$
F(\alpha, \beta)=\sqrt{\frac{(1+\beta) \sin ^{3} \alpha}{\beta+\cos \alpha}} \cdot\left(\frac{3 \beta+1}{\beta^{2}(\beta+1)}\right)^{0.75},
$$

where $\beta$ is the ratio of the sides of the trapezoidal fold $(b / c)$, whereas $\alpha$ is the fold inclination angle.

It should be added that the solution proposed was validated using 22 research models. The solution put forward by Sause and Braxtan [6] also makes it possible to compute wavy webs after approximating wave to a trapezoidal shape. The correction to formula (9) was presented by Hassanein and Kharoob [10] in 2013.

The solutions quoted above concern the trapezoidal web profile. In 2009, Eldib [13] put forward a solution that involved webs of wavy shape corresponding to the trapezoidal geometry. Based on FEM analysis, he determined shear buckling stress for the first buckling load $P_{B}$ that causes the web instability in accordance with Eq. (14). Using regression analysis, Eldib devised Eq. (16) to determine design buckling resistance. The solution in the form of the curve $\tau_{c r} / \tau_{y}-\lambda_{s}$ was referred to the curve produced by Moon [12]. 


$$
\begin{gathered}
\tau_{c r, B}^{e}=\frac{P_{B}}{h_{w} t_{w}}, \\
\lambda_{s}=\sqrt{\frac{\tau_{y}}{\tau_{c r, B}^{y}}}, \\
\left(\frac{1}{\tau_{c r, B}^{y}}\right)^{0.5}=0.002124\left(\frac{R h_{w}}{t_{w}^{2}}\right)^{0.3145}
\end{gathered}
$$

In the formula derived by Eldib [13], the debatable issue is the fact the design shear buckling resistance considerably exceeds shear yield strength $\tau_{y}$, which was not confirmed by experimental investigations [12, 14, 15].

All the formulas for design buckling resistance reported above concern the webs, the folds of which are either trapezoidal or wavy in shape, provided that the latter corresponds to a trapeze. The formulas, however, do not account for the sine wave shape, or the advantageous effect produced by rigid end stiffeners.

\section{Experimental investigations}

Experimental investigations, intended to determine shear buckling resistance, were carried out on two groups of girders. Group "1" contained six girders (M 1.11 WTA 500, M 2.11 WTB 500, M 1.21 WTB 1000, M 1.31 WTB 1000, M 1.41 WTA 1250, M 1.51 WTA 1500 Fig. 2a, b) made of items with different lengths of the side, namely $a=2.16$ and $3.16 \mathrm{~m}$ (distance between end stiffeners), and $b=1.50,1.00 \mathrm{~m}$. Semirigid end stiffeners of girders were made from sheet metal 20 or 25 $\mathrm{mm}$ in thickness (Fig. 2d, e).

In order to determine the impact of end stiffeners on the web shear buckling resistance, four girders that constituted group "2" (M 2.21 - WTA 1000, M 2.31 WTB 1000, M 2.41 WTC 1000, M 2.51 WTA 1500, Fig. 2c) were examined. The girders were made of items having the lengths of $a=2.16 \mathrm{~m}$ and $b=1.50 \mathrm{~m}$. To increase the stiffness of end stiffeners, tee bars were bolted to the sheet metal (Fig. 2f). All the corrugated web girders were designed and made in accordance with literature recommendations and the standards [1, 18].

The items of all girders were butt-connected using M24 bolts, class 10.9 , the bearing capacity of which is greater than that of girders. The bolts satisfy the requirements, from which it follows that rotation in the connection can be treated as a linear function of the rotational stiffness $S_{j}[14,16]$. Girder webs were fabricated, in accordance with the manufacturer's data, using S 235 steel, whereas flanges were made from S 275 steel.

After assembly, the girders were mounted onto the test stand. A frame (FR) (Fig. 3) was employed to load the elements. The load, in the form of a pair of concentrated forces, was transferred by means of the actuator (1) via a dynamometer (2) onto the beam (3), and then to the tested girder (4) at the site of butt connections. Roller (5) and pin (6) supports were used, located between the beam (3) and the girder (4). The girders were secured against lateral torsional buckling (LTB) by additional side supports (8) so that lateral displacements and the rotation of the compression flange could be prevented.



a)

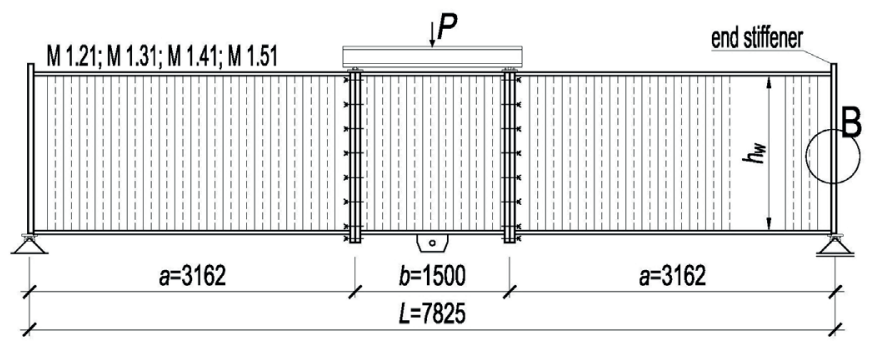

b)

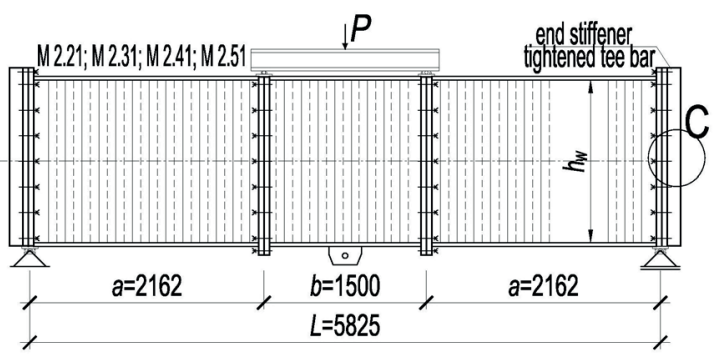

c)

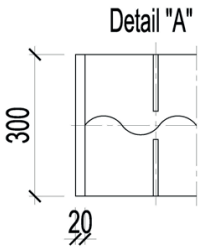

d)



e)

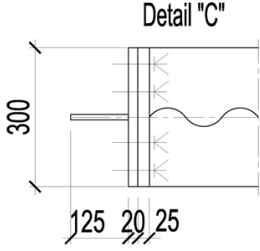

f)
Fig. 2 Corrugated web girders a), b) with semi-rigid end stiffener; c) with end stiffener reinforced by tee-bar; d) detail A; e) detail B; f) detail C

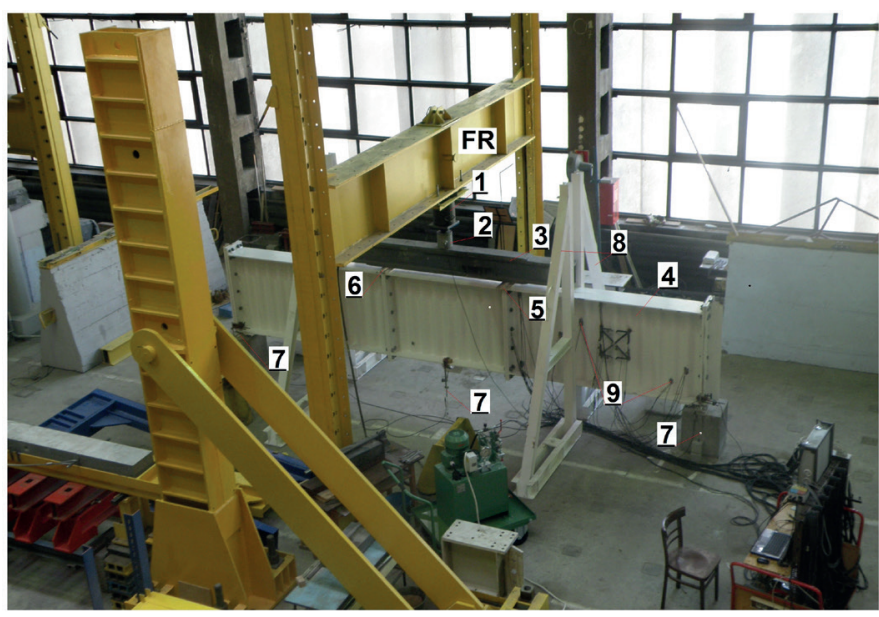

Fig. 3 Girder M2.31 with rigid end stiffener $(300 \times 25 \mathrm{~mm}+$ tee bar $)$ at the test stand 
In the tests, the loading force $P$, the total displacements of the girder $y$, and the settlement of supports were measured. The strain of the corrugated web was measured using array of strain gauges (9). The arrangement of induction sensors (7) for the measurements of the girder vertical displacements is shown in Fig. 3. In addition, the end stiffeners deformation was controlled. The load on girders increased uniformly and the loading rate was up to $20 \mathrm{kN} / \mathrm{min}$.

The array of strain gauges for the measurements of web strain rosettes is shown in Fig. 4.

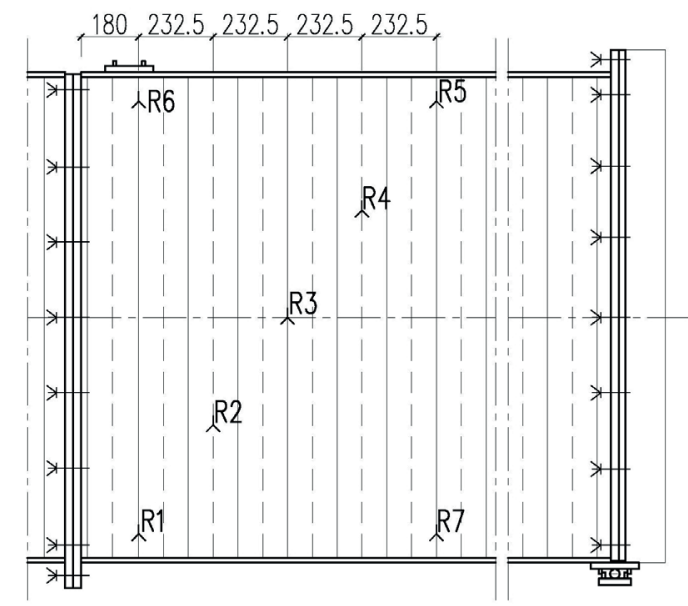

Fig. 4 Location of strain gauges on the girder web M 2.51

\subsection{Loads - displacements paths (LDPs) $P(y)$ of experimental girders}

To find the onset of the corrugated web instability, the strain profile was analysed. Diagonal strain gauges glued onto the web were employed. On the basis of the characteristics of the graphs, the onset of the corrugated web instability was found. The first buckling load $P_{e B}$ was assumed to be located at the point, at which strain vs. load relation stops to be linear in character. Generally, in all girders, the instability onset occurred for strain less than 1\%o. Figure 5 shows exemplary strain vs. load relations for girders M 1.51 and M 2. 51.

Based on the global displacement $y$, measured at the midspan of girders, load-displacement paths LDPs $P(y)$ were derived for all girders. The LDP symbol indicates the relationship between load and displacement of the girder. Figure 6 shows selected LDPs of the following girders: M 1.51 with semirigid end stiffener, and M 2.51 with end stiffener reinforced with a tee bar.

The non-linearity of the global displacement curve $P(y)$ was found to start from coordinate $P_{1}\left(P_{e B}\right)$ following the occurrence of diagonal yield stresses zones in the corrugated web. Yield stresses zones in the corrugated web (coordinate $\left.P_{1}\left(P_{e B}\right)\right)$ in Fig. 4) occurred under load $P=P_{e B}$, shown in Fig. 4 $\mathrm{a}$ and $\mathrm{b}$, which amounted to from 0.71 to 0.92 of the limit load $P_{u R d}$ of the girders.

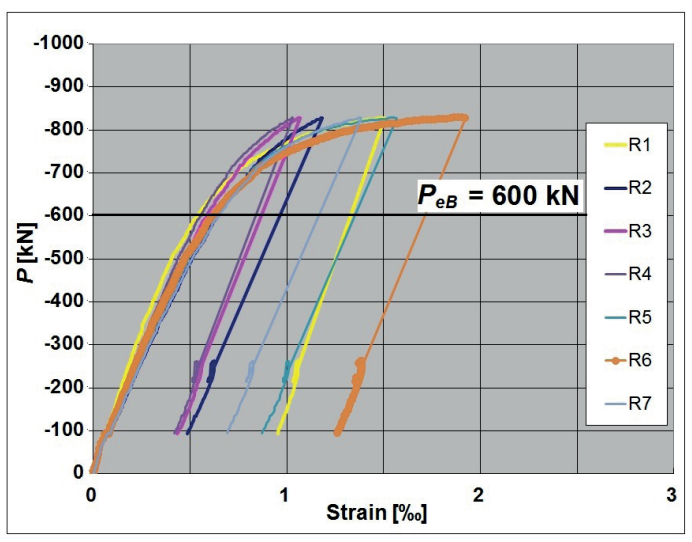

a)



b)

Fig. 5 Strains in the direction $60^{\circ}$ relative to the axis of the web a) girder $\mathrm{M} 1.51$; b) girder M 2. 51



a)

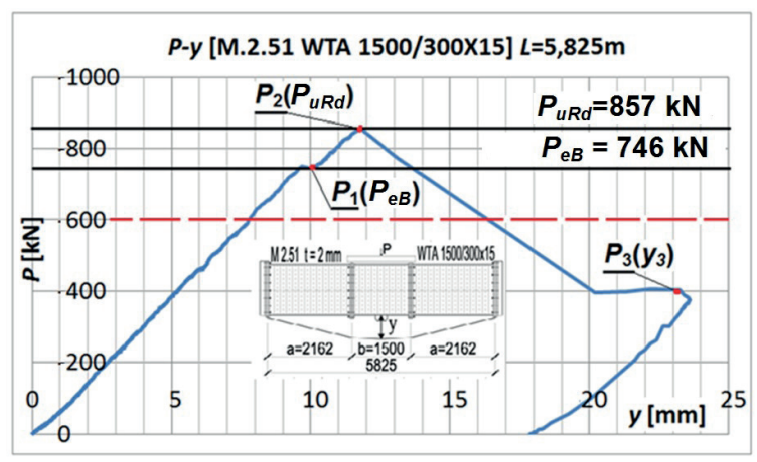

b)

Fig. 6 Load - displacements paths $P(y)$ of girders a) M $1.51(300 \times 25 \mathrm{~mm})$; b) M $2.51(300 \times 25 \mathrm{~mm}+$ tee bar $)$

Thus, characteristic coordinates $P_{1}\left(P_{e B}\right), P_{2}\left(P_{u R d}\right), P_{3}\left(y_{3}\right)$, marked in LDPs $P(y)$ (Fig. 4 a and b), refer to: 
$P_{1}\left(P_{e B}\right)$ - web instability signalled by the onset of the change in the web geometric shape corresponding to the first buckling load $P_{e B}$;

$P_{2}\left(P_{u R d}\right)$ - limit load from girder failure condition $P_{u R d}$ signalled by the completion of the tension field formation;

$P_{3}\left(y_{3}\right)$ - girder unload.

In the global LDP $P(y)$, the linear range of shear displacement was denoted as $0-P_{1}\left(P_{e B}\right)$. With an increase in load and tension field propagation, bending and shear displacements accumulate. The occurrence of yield stresses zones (coordinate $P_{1}\left(P_{e B}\right)$ ) clearly separates the quasi - linear portion of displacements from non-linear displacements. In the range $P_{1}\left(P_{e B}\right)-P_{2}\left(P_{u R d}\right)$, a strong impact of elastic-plastic displacements caused by shear forces in the web on the overall displacements of the girder is observed. As a result, the utilisation of the resistance of flanges is limited.

In girders with a bolted tee bar, end stiffener increased the range of elastic deformation $0-P_{1}\left(P_{e B}\right)$ of the girder. Coordinate $\boldsymbol{P}_{1}\left(\boldsymbol{P}_{e B}\right)$ shifted considerably, which indicates an increase in the first shear buckling load.

An increase in the stiffness of end stiffeners enlarges the zone of the web elastic behaviour in the range $0-P_{1}\left(P_{e B}\right)$. The effect of enhancing the first buckling load of the web diminishes as the ratio of slenderness of end stiffeners to the relative slenderness changes. A broken line in Fig. $6 \mathrm{~b}$ indicates how an increase in the stiffness of end stiffeners due to the bolted tee bars produces an increase in the linear range $0-P_{1}\left(P_{e B}\right)$, that is first buckling load of the sine wave corrugated web of girders compared with girders with end stiffener $25 \mathrm{~mm}$ in thickness.

Table 1 shows the results of experimental investigations into girders. Column 5 lists the values of limit load $P_{u R d}$ measured by force $P$, and Column 6 shows first buckling load $P_{e B}$ measured by force $P$.

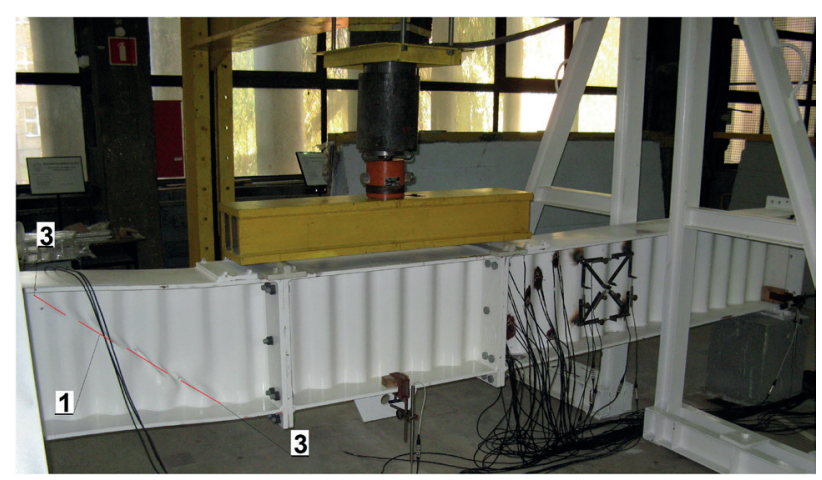

a)

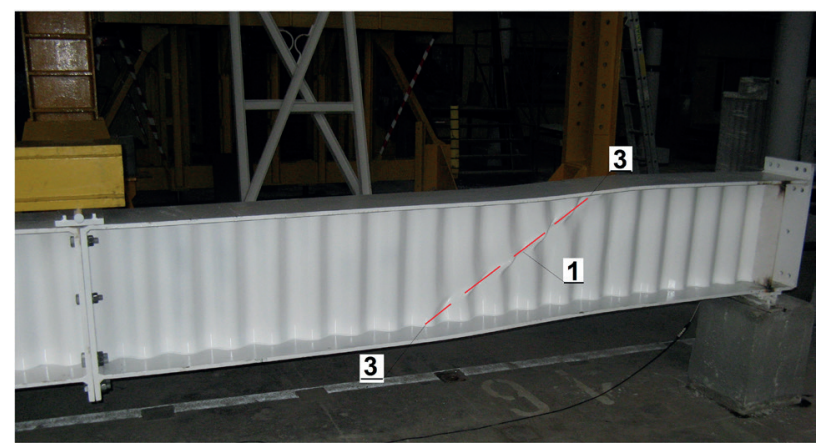

b)

Fig. 7 Failure of corrugated web girders: a) M $1.11(300 \times 20 \mathrm{~mm})$; b) M 2 . $11(300 \times 20 \mathrm{~mm})$

\subsection{Failure modes of experimental girders}

Experimental investigations showed that in girders of " 1 " and "2" group, the web failure occurred abruptly in the zone under a constant shear load. Butt joints of the central segment remained intact in all girders of concern. Instability in the corrugated web started with the local instability of the sine wave panel. After tension line occurrence near the tension flange, yield stresses zone was formed (local instability - L) (Fig. 7), or tension field led to yield stresses zone formation and the skipping of the web waves (interactive instability - I) (Fig. 8). In the final stage, the

Table 1 Experimental results of girders

\begin{tabular}{|c|c|c|c|c|c|c|}
\hline Girder & $\begin{array}{c}\text { Web } \\
h_{w} x t_{w} \\
{[\mathrm{~mm}]}\end{array}$ & End Stiffener & Flange & Failure modes & $\begin{array}{c}\text { Limit load } \\
P_{u, R d} \\
{[\mathrm{kN}]}\end{array}$ & $\begin{array}{c}\text { First buckling load } \\
\qquad P_{e B} \\
{[\mathrm{kN}]}\end{array}$ \\
\hline \multicolumn{7}{|c|}{ "1" group } \\
\hline M 1.11 & $500 \times 2$ & $300 \times 20$ & $300 \times 15$ & $\mathrm{~L}$ & 330 & 260 \\
\hline M 2.11 & $500 \times 2.6$ & $300 \times 20$ & $300 \times 15$ & $\mathrm{~L}$ & 436 & 280 \\
\hline M 1.21 & $1000 \times 2.5$ & $300 \times 25$ & $300 \times 15$ & I & 725 & 570 \\
\hline M 1.31 & $1000 \times 2.6$ & $300 \times 25$ & $300 \times 20$ & I & 745 & 605 \\
\hline M 1.41 & $1250 \times 2$ & $300 \times 25$ & $300 \times 1$ & I & 850 & 600 \\
\hline M 1.51 & $1500 \times 2$ & $300 \times 25$ & $300 \times 15$ & I & 828 & 600 \\
\hline \multicolumn{7}{|c|}{ “2” group } \\
\hline M 2.21 & $1000 \times 2$ & $300 \times 25+$ tee bar & $300 \times 15$ & I & 621 & 570 \\
\hline M 2.31 & $1000 \times 2.5$ & $300 \times 25+$ tee bar & $300 \times 15$ & I & 894 & 740 \\
\hline M 2.41 & $1000 \times 3$ & $300 \times 25+$ tee bar & $300 \times 15$ & I & 1035 & 830 \\
\hline M 2.51 & $1500 \times 2$ & $300 \times 25+$ tee bar & $300 \times 15$ & I & 857 & 746 \\
\hline
\end{tabular}


tension field put a load on girder flanges (3), which caused curving of the lines of yield stresses zones, tangentially to flanges, and also yielding of the flanges in the girder plane.

In group "1" girders with semirigid end stiffeners, large differences between global and elastic resistance of girders were observed. In group " 2 " girders, the use of end stiffeners reduced the range of plastic deformation $P_{1}\left(P_{e B}\right)-P_{2}\left(P_{u R d}\right)$ and increased shear buckling resistance of the web.

In all girders of group "1", the occurrence of the tension field was accompanied by considerable bending of the endplate in the girder plane. In the girders of group " 2 ", the rigid end stiffener restricted the action of the tension field and the resultant change in the interaction of compression and shear components along the generatrix of the web. Consequently, the stiffeners remained straight. In addition, in all girders of group " 2 " with rigid end stiffener, a significant increase in shear buckling resistance and reduction in out-of plane buckling of the corrugated web were found.

Thus, increase in flexural stiffness of end stiffeners in corrugated web girders affects the geometry of tension lines and the area of the web buckling (Fig. 8 a and b). That also enhances shear buckling resistance of the corrugated web.

Recommendations [18] and Eurocode [1], however, disregard the web role in transferring bending moments. However, an increase in the stiffness of end stiffeners leads to web stiffness $E_{z} I_{z}$ increase, resulting in higher elastic resistance of girders.

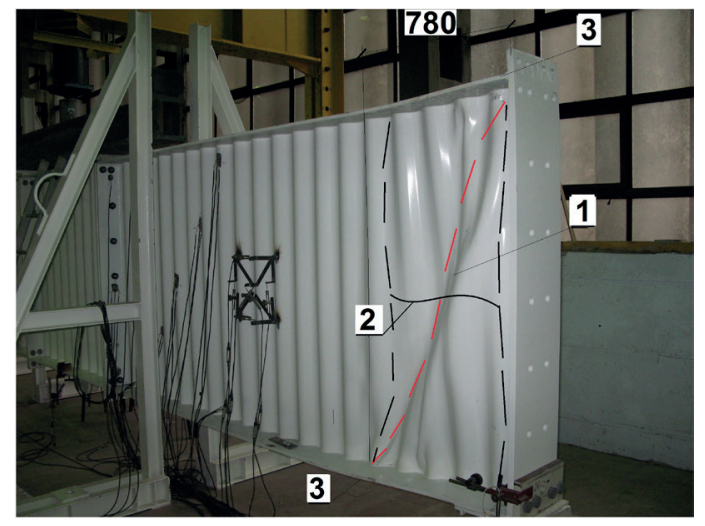

a)



b)

Fig. 8 Failure of corrugated web girders: a) M $1.51(300 \times 25 \mathrm{~mm})$; b) M $2.51(300 \times 25 \mathrm{~mm}+$ tee bar $)$

\subsection{Materials testing of the steel used in experimental girders}

Tests on mechanical properties of steel collected from experimental girders were performed in accordance with EC [24]. The samples were cut out of flanges and corrugated webs. Tests concerning web yield strength were carried out on six samples, randomly collected from along the web fold of each girder (variation coefficient obtained varied from 0.001 to 0.002 ). Tests that involved flanges were conducted on three randomly collected samples. Table 2 shows selected results of materials tests.

Table 2 Material properties

\begin{tabular}{|c|c|c|c|c|c|}
\hline Girder & $\bar{f}_{y}$ & $\bar{f}_{u}$ & $\begin{array}{l}\text { Percentage } \\
\text { total elongation } \\
\text { at maximum } \\
\text { force }\left(F_{m}\right)\end{array}$ & $\begin{array}{c}\text { Percentage } \\
\text { total elongation } \\
\text { at fracture }\end{array}$ & $E$ \\
\hline & [MPa] & [MPa] & {$[\%]$} & {$[\%]$} & [GPa] \\
\hline \multicolumn{6}{|c|}{ web } \\
\hline M 1.11 & 304.4 & 403.5 & 16.4 & 21.5 & \\
\hline M 1.21 & 275.9 & 416.0 & 15.4 & 20.7 & \\
\hline M 1.31 & 260.4 & 403.0 & 16.1 & 20.8 & \\
\hline M 1.41 & 317.8 & 434.3 & 16.8 & 21.6 & \\
\hline M 1.51 & 247.2 & 375.5 & 16.9 & 23.0 & \\
\hline M 2.11 & 266.2 & 390.0 & 17.1 & 22.8 & \\
\hline M 2.21 & 334.3 & 437.5 & 15.4 & 19.3 & \\
\hline M 2.31 & 340.8 & 487.7 & 11.9 & 15.0 & \\
\hline M 2.41 & 325.5 & 422.0 & 15.9 & 19.9 & \\
\hline M 2.51 & 289.3 & 376.8 & 18.4 & 23.1 & \\
\hline \multicolumn{6}{|c|}{ flange } \\
\hline M 1.11 & 298.2 & 454.5 & 22.4 & 29.4 & 202 \\
\hline M 1.21 & 303.4 & 485.5 & 22.6 & 29.4 & 213 \\
\hline M 1.31 & 298.9 & 435.7 & 24.8 & 32.2 & 205 \\
\hline M 1.41 & 281.2 & 443.9 & 23.1 & 30.7 & 202 \\
\hline M 1.51 & 291.1 & 451.8 & 21.9 & 28.8 & 208 \\
\hline M 2.11 & 313.3 & 484.5 & 23.1 & 28.7 & 208 \\
\hline M 2.21 & 322.0 & 465.5 & 17.6 & 24.0 & 202 \\
\hline M 2.31 & 328.0 & 465.6 & 18.6 & 25.0 & 204 \\
\hline M 2.41 & 326.7 & 464.7 & 17.8 & 25.3 & 207 \\
\hline M 2.51 & 290.3 & 432 & 25.0 & 30.7 & 203 \\
\hline
\end{tabular}

Experimental tests show substantial scatter of web yield strength results. The problem was discussed in study [19]. Therefore, for the sake of standardisation, for all 48 numerical models, in FEM analysis the following materials properties were adopted: web yield strength $f_{y}=281 \mathrm{MPa}$, tensile strength $f_{u}=375.5 \mathrm{MP}$ and modulus of elasticity $E=210 \mathrm{GPa}$. As regards flanges, yield strength was $f_{y}=306.7 \mathrm{MPa}$, tensile strength $f_{u}=449.3 \mathrm{MP}$ and modulus of elasticity $E=213 \mathrm{GPa}$. The results of materials tests for girder M 2.52 (WTA $1500 \times$ 2) were adopted [19]. Materials parameters used in numerical analysis are close in values to the yield strength of girders $\mathrm{M}$ 1.21, M 1. 31and M 2.51, which allows a direct comparison with the results of numerical analysis. 


\section{Numerical test}

Numerical estimation of resistance [25] was performed for simply supported girders, shown in Fig. 9, which had been examined experimentally. In numerical models employed in FEM analysis, geometry of girders shown in Fig. 2 was represented. Due to the fact that all end-plate connections used in experimental investigations were rigid, in numerical tests they were replaced with intermediate stiffeners, the thickness of which was equal to that of sheet plate connections, i.e. $50 \mathrm{~mm}$. In corrugated web girders, the failure mode is affected by the dimensions of the web, end stiffeners and flanges. Therefore, accurate measurements of individual girder components were taken. They concerned the web height, thickness and wave profile (which was done in the materials tests). The dimensions of intermediate and support end stiffeners and flanges were checked (Table 1). Additionally, measurements of the flange curvature and girder rectilinearity were taken. The girders did not show geometric imperfections in the longitudinal or cross sections. That was of key importance as the girder cross section imperfections could affect the failure mode of the corrugated web, changing it from local to interactive one. Additionally, the girders were secured against lateral torsional buckling to avoid the impact of the girder LTB on the web failure mode.

FEM analysis was carried out using 48 numerical models that were divided into two groups: those with semirigid end stiffeners (in 12 of them $a=3.16$, and in the remaining 12 girders $a=2.16$ ), and those with end stiffeners reinforced with tee bars (again, in half of them, i.e. 12 girders, $a=3.16$, and in the other half $a=2.16$ ). In order to confirm that the length of corrugated web panel between stiffeners does not affect the resistance, girders were further differentiated with respect to the side length $a$. Webs 500, 1000, 1250 and $1500 \mathrm{~mm}$ in height, had the thickness of 2, 2.5 and $3 \mathrm{~mm}$ (Fig. 9) (Table 3).

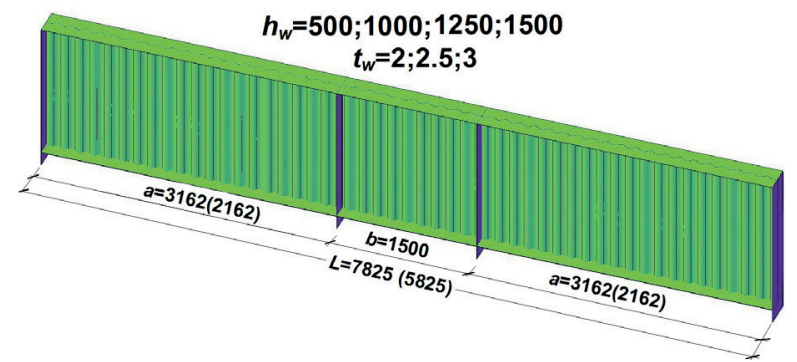

a)

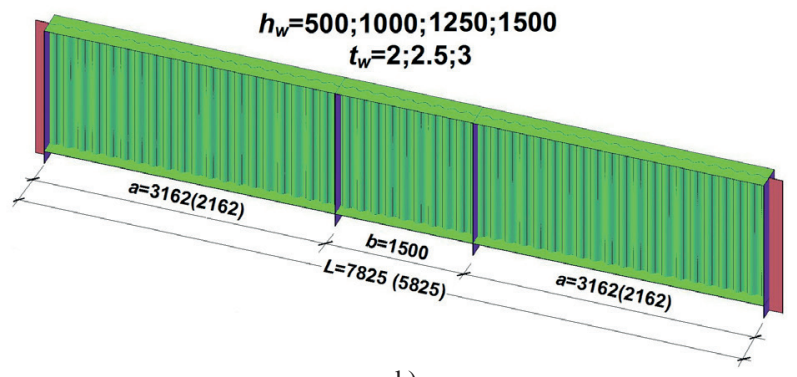

b)

Fig. 9 Numerical models: a) end stiffener $300 \times 25$; b) end stiffener $300 \times 25$ + tee bar
Web wave was modelled in the CAD environment as a sine wave. Then, it was transferred to the Abaqus software, where the ultimate web shape was created. The web shape was in the required height and length. Flanges, stiffeners and corrugated webs were modelled using S4R shell elements (a 4- node doubly curved shell with reduced integration, which has six degrees of freedom at each node, three translations and three rotations) and also $\mathrm{S} 3$ shell elements. To make them, from 36,488 (model $h_{w}=500 \mathrm{~mm} L=5,825$ ) to 96,417 (model $h_{w}=$ $1,500 \mathrm{~mm} L=7,825)$ finite elements were employed.

Table 3 Current numerical program

\begin{tabular}{|c|c|c|c|c|c|c|}
\hline $\begin{array}{l}h_{w} \\
{[\mathrm{~mm}]}\end{array}$ & $\begin{array}{c}t_{w} \\
{[\mathrm{~mm}]}\end{array}$ & $\begin{array}{c}\text { End Stiffener } \\
{[\mathrm{mm}]}\end{array}$ & $\begin{array}{c}a \\
{[\mathrm{~mm}]}\end{array}$ & $\begin{array}{c}b \\
{[\mathrm{~mm}]}\end{array}$ & $\begin{array}{c}L \\
{[\mathrm{~mm}]}\end{array}$ & $\begin{array}{l}\text { Number } \\
\text { of models }\end{array}$ \\
\hline $500-1500$ & $2 ; 2.5 ; 3$ & $300 \times 25$ & 3162 & 1500 & 7825 & 12 \\
\hline $500-1500$ & $2 ; 2.5 ; 3$ & $\begin{array}{l}300 \times 25 \\
+ \text { tee bar }\end{array}$ & 3162 & 1500 & 7825 & 12 \\
\hline $500-1500$ & $2 ; 2.5 ; 3$ & $300 \times 25$ & 2162 & 1500 & 5825 & 12 \\
\hline $500-1500$ & $2 ; 2.5 ; 3$ & $\begin{array}{l}300 \times 25 \\
+ \text { tee bar }\end{array}$ & 2162 & 1500 & 5825 & 12 \\
\hline
\end{tabular}

\subsection{Type of numerical analysis}

In the numerical analysis carried out for this study, the Riks method was used. In the Riks method the load is applied proportionally in several load steps and path parameter is the control parameter. The method allows finding a solution to the problem regardless of the web buckling mode. That involves identifying load-displacement equilibrium at the end of each iterative step. While seeking load-displacement equilibrium, load can be increased or decreased until ultimate resistance is reached in accordance with [27]. This is a method often used in static analysis, as it is one of the best methods for non-linear analysis.

\subsection{Load and boundary conditions}

In all numerical models (Fig. 9), the adopted boundary conditions were the same as for experimental girders (Fig. 2).

As regards the left support, the possibility of vertical $\left(U_{z}=\right.$ $0)$, horizontal $\left(U_{x}=0\right)$ and lateral $\left(U_{y}=0\right)$ displacements was eliminated. As for the right support, the possibility of vertical $\left(U_{z}=0\right)$, and lateral $\left(U_{y}=0\right)$ displacements was ruled out. To prevent lateral torsional buckling (LTB), the possibility of lateral displacements $\left(U_{y}=0\right)$ and twist rotation about x-axis $\left(\phi_{x}=0\right)$ of intermediate stiffeners was excluded. (Fig. 10). Conversely, experimental girders were supported on pin support , and on roller bearing support.

Longitudinal load on stiffeners (Fig. 10) was a pair of concentrated forces $2 \times P / 2$, which was applied to intermediate stiffeners of the models. At the sites of load application, additional steel plates, $20 \mathrm{~mm}$ in thickness, were used, as it was the case with actual girders. 


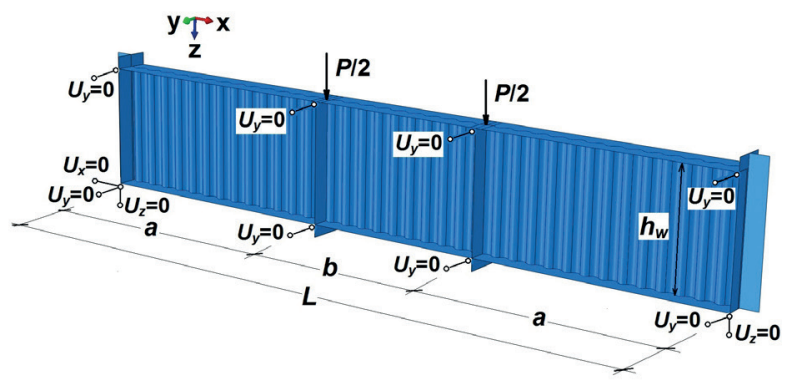

Fig. 10 Boundary condition and load application to girder

The loading step was linear until the occurrence of the girder instability. Next, the step became non-linear and remained so until the occurrence of the limit load. Beyond the limit load, the model was unloaded.

\subsection{Load - displacements paths of girder numerical models (LDPs) $P(y)$}

In corrugated webs, the sinusoidal shape is obtained in accordance with the curve incorporated into the rolling control program. Therefore, the measurements confirmed the sine wave shape. The automation of sheet metal cutting, flange welding to the web and end stiffener welding significantly reduces the occurrence of geometric imperfections in the longitudinal and cross sections of fabricated girders. However, small differences in the web thickness were found. That especially refers to the web with the nominal thickness of $2.5 \mathrm{~mm}$. The experimental girders were $2 \mathrm{~mm}, 2.5 \mathrm{~mm} ; 2.6 \mathrm{~mm}$ and 3 mm thick.

At the first stage of the numerical model validation, the 'perfect' model without any imperfections was employed. The dimensions of the web, flanges, end stiffeners obtained through measurements, and the also the web shape were accurately mapped. In accordance with EC3 [27], in numerical tests, the material model was based on the results of materials tests conducted to find out the properties of steel used in experimental investigations. The material model accounted for Huber-Mises-Hencky yield criterion. The buckling load ratio $P_{e B I N V} / P_{e B F E}$ was $21-26 \%$.

The subsequent validation step involved an 'imperfect' model. The initial imperfection consisted in thinning the web by $1 / 10$ of its thickness [26]. Direct comparison of the results of experimental investigations and numerical analysis, namely girders M $1.21(1000 \times 2.5)$ and M $2.51(1500 \times 2)$, and imperfect numerical models $1000 \times 2.5$ and $1500 \times 2$ shows that the estimates of the limit load $P_{u R d}$ from FEM analysis turned out to be convergent with experimental results (see Table 2 and Table 4). As regards the estimates of first buckling load $P_{e B}$, FEM results were $10-15 \%$ greater compared with experimental results. The next stage of validation dealt with the comparison of the failure modes in numerical and experimental models, and of load displacement paths. All subsequent numerical models were marred with initial imperfection related to a reduction in the web thickness. A slight difference in results was caused by the skidding of the roller bearing used in experimental investigations. That resulted in a small reduction in the web first buckling load when compared with the support on the edge end stiffener employed in FEM analysis. That also produced an increase in displacements $y$ in experimental girders compared with numerical models. In all other numerical girders, the first buckling load and limit load results were diminished because of lower yield strength values used in the analysis.

On the basis of displacement $y$ measured at the midspan and load $P$, global LDPs $P(y)$ were obtained for all numerical models of girders with semirigid end stiffeners and end stiffeners reinforced with tee bars.

Figures $11 \mathrm{~b}$, and $12 \mathrm{~b}$ show exemplary LDPs $P(y)$ of numerical models of girders with semirigid end stiffeners $1000 \times$ 2.5 , and end stiffeners reinforced with tee bars $1500 \times 2$. The moment of instability of the web of numerical models $P_{1}\left(P_{e B}\right)$ was assumed to be a clear boundary between the straight-line portion and the non-linear part of the global displacement (Figs. 11b, 12b).

In global LDPs $P(y)$, the coordinates of characteristic points, namely $P_{1}\left(P_{e B}\right)$ and $P_{2}\left(P_{u R d}\right)$, were marked. The coordinates refer to the resistance of numerical models of girders and they correspond to characteristic coordinates for experimental investigations.

Figures 11 and 12 show a comparison of LDPs $P(y)$ for numerical models of girders obtained on the basis of FEM analysis, and those resulting from experimental investigations. Profiles of load-displacement paths for FEM analysis and experimental investigations are similar. After the web instability at point $P_{1}\left(P_{e B}\right)$, a non-linearity was found in LDP $P(y)$, which was followed by a curvilinear increment until limit load was reached (point $P_{2}\left(P_{u R d}\right)$ ). Additionally, in experimental girders, a longer range of postbuckling resistance $P_{1}\left(P_{e B}\right)$ $-P_{2}\left(P_{u R d}\right)$ was observed.

The adjustment of the results of design buckling resistance was proposed in the theoretical solution, presented in Chapters 6 and 7, which accounts for the effect of variation in yield strength.

FEM analysis confirmed that in girders to which tee bars were bolted, the range of plastic deformations $P_{1}\left(P_{e B}\right)$ increased, which indicates an increase in the shear buckling force. In addition, both experimental investigations and FEM analysis show that an alteration in the ratios $a / h_{w}$ and $r / t_{w}$ (radius of the web fold /web thickness) led to a change in the geometric mode of the web instability from a local to an interactive one.

Table 4 shows FEM estimates of the resistance of girders. Columns 4 and 5 give limit load $P_{u R d}$ measured with force $P$, Columns 6 and 7 show first buckling load $P_{e B}$ measured with force $P$. Columns 8 and 9 list the ratio of loads $P_{e B} / P_{u R d}$. 


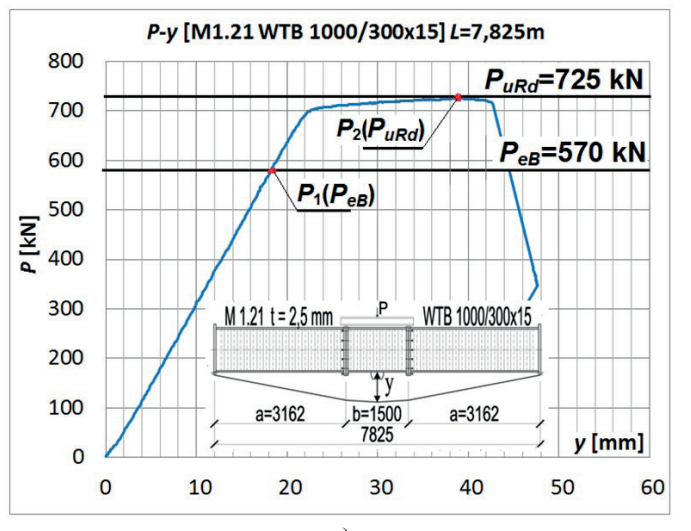

a)

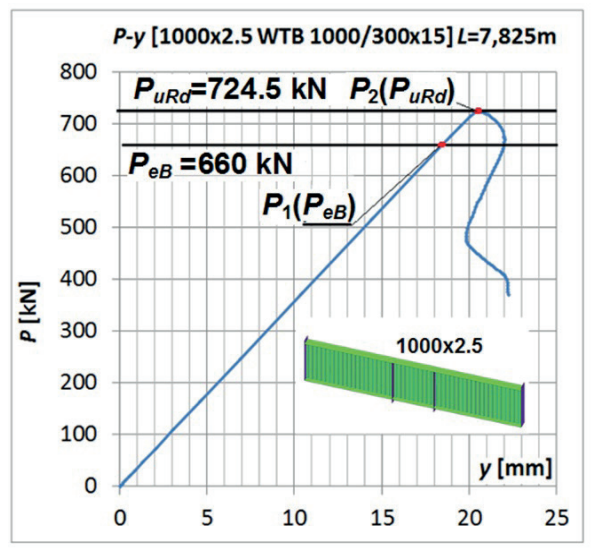

b)

Fig. 11 Comparison of LDPs $P(y)$ a) test M 1.21 ; b) FEM $1000 \times 2.5$ (the Risk method)

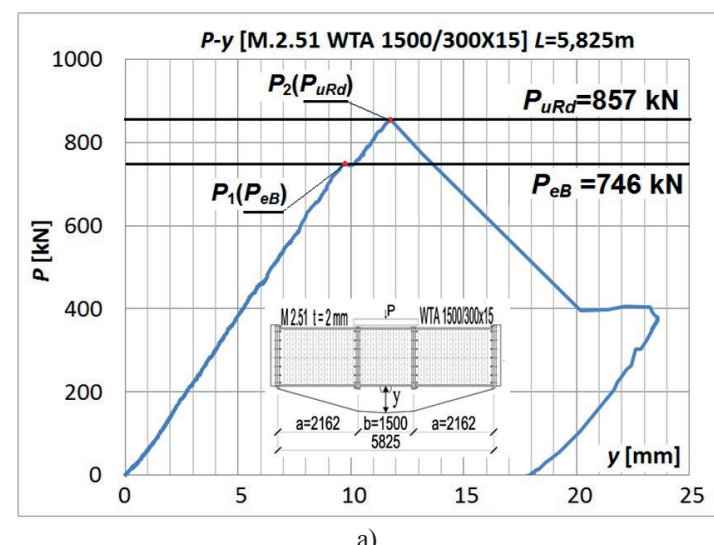

a)

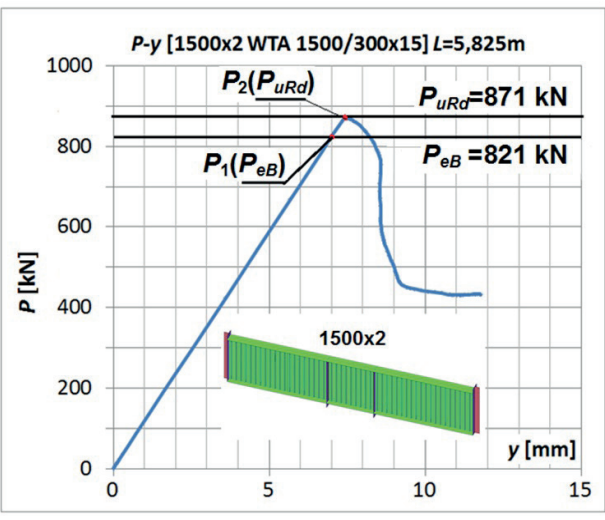

b)

Fig. 12 Comparison of LDPs $P(y)$ a) test M 2.51; b) FEM $1500 \times 2$ (the Risk method)

Table 4 Numerical results of girders (The Riks method)

\begin{tabular}{|c|c|c|c|c|c|c|c|c|}
\hline $\begin{array}{l}\text { Girder } \\
h_{w} \times t_{w} \\
{[\mathrm{~mm}]}\end{array}$ & End Stiffener & Failure modes & $\begin{array}{l}\text { Limit load } \\
\qquad \begin{array}{c}P_{u, R d} \\
a=3 \mathrm{~m} \\
{[\mathrm{kN}]}\end{array}\end{array}$ & $\begin{array}{c}\text { Limit load } \\
P_{u, R d} \\
a=2 \mathrm{~m} \\
{[\mathrm{kN}]}\end{array}$ & $\begin{array}{c}\text { First buckling load } \\
\begin{array}{c}P_{e B} \\
a=3 \mathrm{~m} \\
{[\mathrm{kN}]}\end{array}\end{array}$ & $\begin{array}{l}\text { First buckling load } \\
\qquad \begin{array}{c}P_{e B} \\
a=2 \mathrm{~m} \\
{[\mathrm{kN}]}\end{array}\end{array}$ & $\begin{array}{c}P_{e B} / P_{u, R d} \\
a=3 \mathrm{~m} \\
{[\%]}\end{array}$ & $\begin{array}{c}P_{e B} / P_{u, R d} \\
a=2 \mathrm{~m} \\
{[\%]}\end{array}$ \\
\hline $500 \times 2$ & $300 \times 25$ & $\mathrm{~L}$ & 288.8 & 290.1 & 262.1 & 265.3 & 0.91 & 0.91 \\
\hline $500 \times 2.5$ & $300 \times 25$ & $\mathrm{~L}$ & 361.7 & 363.8 & 330.3 & 330.8 & 0.91 & 0.91 \\
\hline $500 \times 3$ & $300 \times 25$ & $\mathrm{~L}$ & 434.4 & 437.6 & 395.1 & 397.3 & 0.91 & 0.91 \\
\hline $1000 \times 2$ & $300 \times 25$ & I & 577.9 & 579.6 & 527.1 & 527.2 & 0.91 & 0.91 \\
\hline $1000 \times 2.5$ & $300 \times 25$ & I & 724.5 & 726.3 & 659.7 & 660.0 & 0.91 & 0.91 \\
\hline $1000 \times 3$ & $300 \times 25$ & I & 870.2 & 872.2 & 791.3 & 791.8 & 0.91 & 0.91 \\
\hline $1250 \times 2$ & $300 \times 25$ & I & 722.8 & 725.7 & 659.9 & 660.1 & 0.91 & 0.91 \\
\hline $1250 \times 2.5$ & $300 \times 25$ & I & 904.8 & 907.8 & 823.7 & 829.9 & 0.91 & 0.91 \\
\hline $1250 \times 3$ & $300 \times 25$ & I & 1086.7 & 1089.7 & 988.3 & 995.7 & 0.91 & 0.91 \\
\hline $1500 \times 2$ & $300 \times 25$ & I & 867.9 & 870.4 & 796.2 & 790.7 & 0.92 & 0.91 \\
\hline $1500 \times 2.5$ & $300 \times 25$ & I & 1085.9 & 1088.3 & 989.6 & 976.0 & 0.91 & 0.90 \\
\hline $1500 \times 3$ & $300 \times 25$ & I & 1303.9 & 1306.4 & 1185.5 & 1179.9 & 0.91 & 0.90 \\
\hline $500 \times 2$ & $300 \times 25+$ tee bar & $\mathrm{L}$ & 288.9 & 290.1 & 261.9 & 270.3 & 0.91 & 0.93 \\
\hline $500 \times 2.5$ & $300 \times 25+$ tee bar & $\mathrm{L}$ & 361.7 & 363.9 & 341.7 & 338.0 & 0.94 & 0.93 \\
\hline $500 \times 3$ & $300 \times 25+$ tee bar & $\mathrm{L}$ & 434.6 & 437.6 & 409,0 & 404.6 & 0.94 & 0.92 \\
\hline $1000 \times 2$ & $300 \times 25+$ tee bar & I & 578.0 & 579.7 & 556.5 & 555.9 & 0.96 & 0.96 \\
\hline $1000 \times 2.5$ & $300 \times 25+$ tee bar & I & 724.7 & 726.7 & 695.5 & 695.8 & 0.96 & 0.96 \\
\hline $1000 \times 3$ & $300 \times 25+$ tee bar & I & 870.6 & 872.3 & 843.5 & 834.7 & 0.97 & 0.96 \\
\hline $1250 \times 2$ & $300 \times 25+$ tee bar & I & 724.1 & 726.0 & 695.7 & 694.6 & 0.96 & 0.96 \\
\hline $1250 \times 2.5$ & $300 \times 25+$ tee bar & I & 906.2 & 908.3 & 868.7 & 868.0 & 0.96 & 0.96 \\
\hline $1250 \times 3$ & $300 \times 25+$ tee bar & I & 1088.2 & 1090.4 & 1041.9 & 1041.1 & 0.96 & 0.95 \\
\hline $1500 \times 2$ & $300 \times 25+$ tee bar & I & 869.4 & 871.2 & 839.5 & 821.3 & 0.97 & 0.94 \\
\hline $1500 \times 2.5$ & $300 \times 25+$ tee bar & I & 1087.6 & 1089.4 & 1042.9 & 1013.8 & 0.96 & 0.93 \\
\hline $1500 \times 3$ & $300 \times 25+$ tee bar & I & 1305.8 & 1307.9 & 1216.7 & 1220.9 & 0.93 & 0.93 \\
\hline
\end{tabular}




\subsection{Failure modes in numerical models of girders}

Figures 13 and 14 show different failure modes that occur when semirigid end stiffeners, and end stiffeners reinforced with tee bars are used. The web failure in numerical models of girders occurred rapidly in the near-support area. Intermediate end stiffeners were not affected.

In girders $h_{w}=500, \mathrm{~mm}$ tension field (1) resulted in the formation of the yield stresses zone (Fig. 12) related to the web local instability. That imposed a load on girder flanges (3) leading to the curving of the lines of yield stresses zones tangentially to flanges, and the yielding of flanges in the girder plane. As regards girders $h_{w}=500 \mathrm{~mm}$, the failure mode of the models with semirigid and rigid end stiffeners was very similar (Fig. $12 \mathrm{a}$ and b).

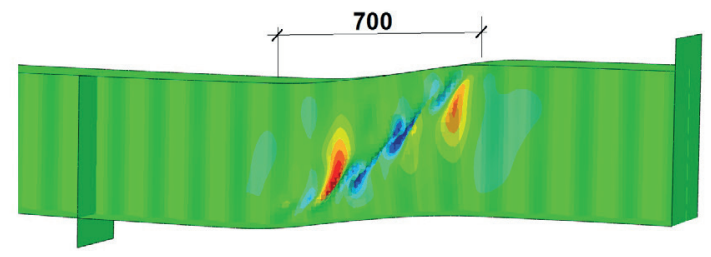

a)

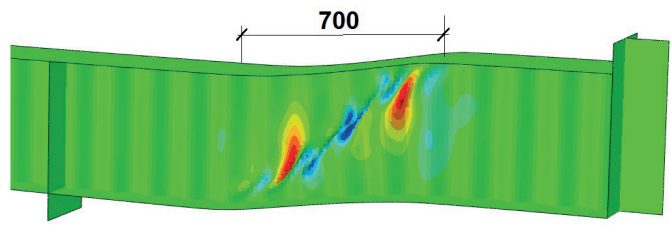

b)

Fig. 13 Failure modes of numerical models: a) $500 \times 2.5$ (stiffener $300 \times 25$; b) $500 \times 2.5$ (stiffener $300 \times 25+$ tee bar)



a)

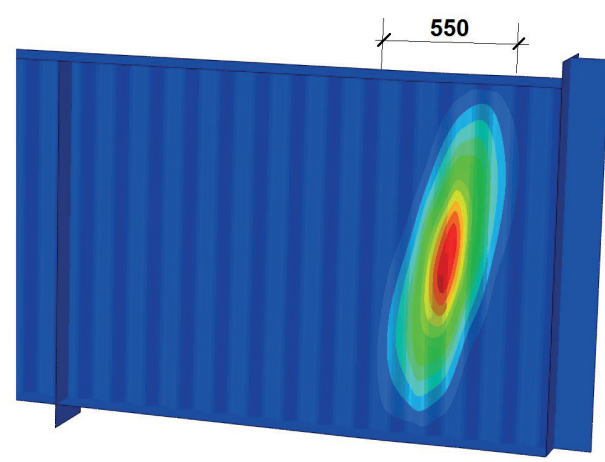

b)

Fig. 14 Failure modes of numerical models: a) $1500 \times 3$ (stiffener $300 \times 25$; b) $1500 \times 3$ (stiffener $300 \times 25+$ tee bar)
In girders $h_{w}=1000,1250$ and $1500 \mathrm{~mm}$, after the development of tension line (1), tension field led to the formation of yield stresses zone and buckling of the opposite web waves (interactive instability - I). Then, a load was imposed on the flanges of girders (3) causing the yield of flanges in the girder plane (Fig. $14 \mathrm{a}$ and b). In girders with semirigid end stiffener, the end plate was bent in the girder plane, which resulted from the action of the tension field. Conversely, the end stiffener reinforced with a tee bar restricted the action of the tension field, and thus a resultant interaction of compression and shear along the web generatrix.

Consequently, end stiffeners remained straight (Fig. 14 a and b). In all girders $h_{w}=1000,1250$ and $1500 \mathrm{~mm}$ with reinforced end stiffener, shear buckling resistance increased and the area of the corrugated web buckling out of the plane was reduced.

Failure modes in girders used in experimental investigations and those employed in FEM analysis turned out to be very similar (Fig. 15 a and b). Like in experimental investigations, the effect of the length of span $a$ on the results of numerical test was very low, and therefore negligible (Table 4).



a)

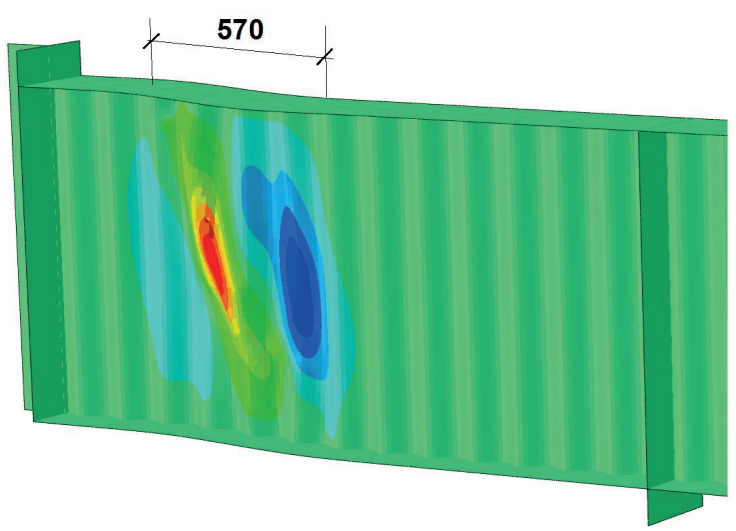

b)

Fig. 15 Comparison of failure modes: a) M 2.41(1000 $\times 3$ stiffener $300 \times 25$ + tee bar; b) $1000 \times 3$ (stiffener $300 \times 25+$ tee bar) 


\section{The proposed approach}

The occurrence of yield stresses zones on the corrugated web is an onset of permanent deformation of the web. That indicates the web instability that is reflected in the curving of LDP $P(y)$ in the range $P_{1}\left(P_{e B}\right)-P_{2}\left(P_{u R d}\right)$. The process of tension field development ends in the formation of the permanent yield zone in the web and the jumping of the neighbouring web waves (Figs. 7, 8, 13, 14).

Based on experimental investigations and numerical tests, shear buckling resistance at the instability point for the corrugated web was estimated from relation (17). The values are listed in Tables 5 and 6 :

$$
\tau_{c r, B}=0.5 P_{e B} / h_{w} t_{w},
$$

where: $P_{e B}$ - first buckling load; $h_{w}, t_{w}-$ web height and thickness.

The results of numerical analyses and experimental investigations indicate that methods currently used for the determination of design shear buckling resistance [EC3] do not account for interaction between local and global mode of the corrugated web instability. In addition, the phenomenon of increase in buckling stress related to the use of rigid end stiffeners is not taken into consideration in present methods.

Therefore, a new approach to the determination of design shear buckling resistance was proposed. It relies on the estimation of shear interactive buckling resistance $\tau_{c r l, 6}$.

In order to determine shear interactive buckling resistance $\tau_{c r,, 6}$, it is necessary to estimate local $\tau_{c r, L}$ and global $\tau_{c r, G}$ shear buckling stress from classical equations (18) and (19) [1]:

$$
\begin{gathered}
\tau_{c r, L}=k_{L} \frac{\pi^{2} E}{12\left(1-v^{2}\right)}\left[\frac{t_{w}}{s}\right]^{2}, \\
\tau_{c r, G}=k_{G} \frac{\left(D_{y} D_{z}^{3}\right)^{1 / 4}}{t_{w} h_{w}^{2}},
\end{gathered}
$$

In the proposed semi-empirical solution, at local instability, the upper limit of the coefficient $k_{L}$ was adopted in accordance with Eq. (20):

$$
k_{L}=\left(5.34+\frac{a_{w}^{0.5} \cdot S}{h_{w} t_{w}^{0.5}}+\frac{h_{w}}{a}\right),
$$

It was made dependent on: $s=89 \mathrm{~mm}-$ length of the arc of half-sine wave, $a_{w}=40 \mathrm{~mm}-$ height of the two half-sine waves, $a-$ span between stiffeners.

As regards global instability, the upper limit of the coefficient $k_{G}$ was assumed to be $k_{G, S}=42.1$ for semirigid end stiffeners, and $k_{G, R}=48.6$ for rigid end stiffeners.

Consequently, the proposed interactive shear buckling resistance $\tau_{c r l, 6}$ can be written using formula (21):

$$
\tau_{c r I, 6}=\frac{\tau_{c r, L} \cdot \tau_{c r, G}}{\left(\tau_{c r, L}^{6}+\tau_{c r, G}^{6}\right)^{\frac{1}{6}}},
$$

Finally, the proposed shear buckling resistance takes the form (22) for corrugated web girders with semirigid end stiffener, and (23) for girders with rigid end stiffener:

$$
\begin{gathered}
\tau_{n, B A}=\tau_{y}\left[\frac{2}{\lambda_{I, 6}^{6}+7}\right]^{\frac{1}{6}}, \\
\tau_{n, B A}=\tau_{y}\left[\frac{2}{\lambda_{I, 6}^{6}+5}\right]^{\frac{1}{6}},
\end{gathered}
$$

where: $\lambda_{l, 6}$ - interactive slenderness dependent on interactive shear buckling resistance $\tau_{c r l, 6}$ :

$$
\lambda_{I, 6}=\sqrt{\frac{\tau_{y}}{\tau_{c r I, 6}}},
$$

Formulas (22) and (23) appropriately describe framed webs of girders that vary from 500 to $1500 \mathrm{~mm}$ in height. The formulas produce the results that are congruent with shear buckling resistance values obtained from experimental investigations and numerical tests acc. equation (17).

\section{Results and evaluation of the adopted solution}

All girders failed due to shear force loading. The failure was caused by local (L) or interactive (I) mode of instability of the corrugated web. In girders with reinforced end stiffener, the range of elastic deformation $0-P_{1}\left(P_{e B}\right)$ increased, which led to higher values of design shear buckling resistance.

Tables 5 and 6 (Columns 2, 3 and 4) present the collation of the results of design buckling resistance obtained from the experiments $\tau_{I N V}$, numerical analysis $\tau_{F E}$, proposed by Sause and Braxtan $\tau_{n, S B}$, EC $3 \tau_{n, E C}$, and also according to the solution put forward in this study $\tau_{n, B A}$ for girders with semirigid and reinforced end stiffeners.

Normalized shear buckling resistance obtained from experimental investigations $\left(\tau_{I N V} / \tau_{y}\right)$ and numerical analysis $\left(\tau_{F E} / \tau_{y}\right)$ was compared with normalized resistance determined on the basis of the proposal by Sause and Braxtan [6] $\left(\tau_{n, S B} / \tau_{y}\right)$, EC 3 [1] $\left(\tau_{n, E C} / \tau_{y}\right)$, and also computed according to the solution put forward in this study $\left(\tau_{n, B A} / \tau_{y}\right)$ (Tables 5 and 6 ). As regards the proposal by Sause and Braxtan [6], the web sine shape was approximated using a trapezoidal fold, as per Fig. 16 acc. [18]:

It should be noted that in the elastic-plastic zone, normalized resistance acc. Sause and Braxtan [6] $\left(\tau_{n, S B} / \tau_{y}\right)$ is slightly lower when compared with experimental $\left(\tau_{I N V} / \tau_{y}\right)$ and numerical $\left(\tau_{F E} /\right.$ $\tau_{y}$ ), results, especially for girders with reinforced end stiffener.

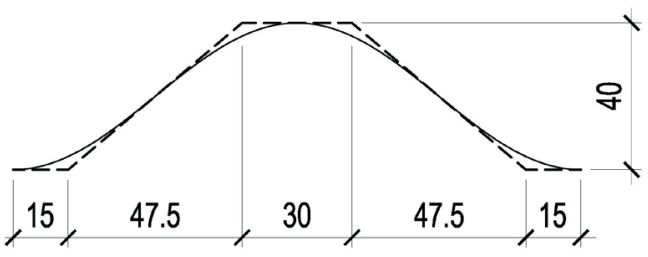

Fig. 16 Fold equivalent section for a single web wave 
Table 5 Comparison of experimental, FEM, design [6, 1] and proposed resistances (22) (for semirigid stiffener)

\begin{tabular}{|c|c|c|c|c|c|c|c|c|c|c|c|}
\hline $\begin{array}{l}\text { Girder } \\
h_{w} \times t_{w} \\
{[\mathrm{~mm}]}\end{array}$ & $\begin{array}{c}\tau_{I N V} \\
{[\mathrm{MPa}]}\end{array}$ & $\begin{array}{c}\tau_{F E} \\
a=3.16 \\
{[\mathrm{MPa}]}\end{array}$ & $\begin{array}{c}\tau_{F E} \\
a=2.16 \\
{[\mathrm{MPa}]}\end{array}$ & $\frac{\tau_{I N V}}{\tau_{y}}$ & $\begin{array}{c}\frac{\tau_{F E}}{\tau_{y}} \\
a=3,16\end{array}$ & $\begin{array}{c}\frac{\tau_{F E}}{\tau_{y}} \\
a=2,16\end{array}$ & $\frac{\tau_{n, S B}}{\tau_{y}}$ & $\frac{\tau_{n, E C}}{\tau_{y}}$ & $\frac{\tau_{n, B A}}{\tau_{y}}$ & $\frac{\tau_{n, B A}}{\tau_{I N V}}$ & $\frac{\tau_{n, B A}}{\tau_{F E}}$ \\
\hline 1 & 2 & 3 & 4 & 5 & 6 & 7 & 8 & 9 & 10 & 11 & 12 \\
\hline $500 \times 2$ & 130.0 & 131.0 & 132.7 & 0.77 & 0.81 & 0.82 & 0.79 & 0.86 & 0.81 & 1.05 & 1.00 \\
\hline $500 \times 2.5$ & 112.0 & 132.1 & 132.3 & 0.77 & 0.81 & 0.82 & 0.79 & 0.91 & 0.81 & 1.06 & 1.00 \\
\hline $500 \times 3$ & & 131.7 & 132.4 & & 0.81 & 0.82 & 0.79 & 0.95 & 0.81 & & 1.00 \\
\hline $1000 \times 2$ & & 131.8 & 131.8 & & 0.81 & 0.81 & 0.79 & 0.83 & 0.81 & & 1.00 \\
\hline $1000 \times 2.5$ & 114.0 & 131.9 & 132.0 & 0.78 & 0.81 & 0.81 & 0.79 & 0.88 & 0.81 & 1.04 & 1.00 \\
\hline $1000 \times 3$ & & 131.9 & 132.0 & & 0.81 & 0.81 & 0.79 & 0.93 & 0.81 & & 1.00 \\
\hline $1250 \times 2$ & 120.0 & 132.0 & 132.0 & 0.71 & 0.81 & 0.81 & 0.79 & 0.82 & 0.81 & 1.14 & 0.99 \\
\hline $1250 \times 2.5$ & & 131.8 & 132.8 & & 0.81 & 0.82 & 0.79 & 0.88 & 0.81 & & 0.99 \\
\hline $1250 \times 3$ & & 131.8 & 132.7 & & 0.81 & 0.82 & 0.79 & 0.92 & 0.81 & & 1.00 \\
\hline $1500 \times 2$ & 100.0 & 132.7 & 131.8 & 0.73 & 0.82 & 0.81 & 0.79 & 0.82 & 0.79 & 1.10 & 0.97 \\
\hline $1500 \times 2.5$ & & 132.0 & 130.1 & & 0.81 & 0.80 & 0.79 & 0.87 & 0.80 & & 0.98 \\
\hline $1500 \times 3$ & & 131.7 & 131.1 & & 0.81 & 0.81 & 0.79 & 0.92 & 0.80 & & 0.99 \\
\hline AVG. & & & & 0.74 & 0.81 & 0.81 & 0.79 & 0.88 & 0.81 & 1.09 & 0.99 \\
\hline
\end{tabular}

Table 6 Comparison of experimental, FEM, design [6, 1] and proposed resistances (23) (for rigid stiffener)

\begin{tabular}{|c|c|c|c|c|c|c|c|c|c|c|c|}
\hline $\begin{array}{l}\text { Girder } \\
h_{w} \times t_{w} \\
{[\mathrm{~mm}]}\end{array}$ & $\begin{array}{c}\tau_{I N V} \\
{[\mathrm{MPa}]}\end{array}$ & $\begin{array}{c}\tau_{F E} \\
a=3.16 \\
{[\mathrm{MPa}]}\end{array}$ & $\begin{array}{c}\tau_{F E} \\
a=2.16 \\
{[\mathrm{MPa}]}\end{array}$ & $\frac{\tau_{I N V}}{\tau_{y}}$ & $\begin{array}{c}\frac{\tau_{F E}}{\tau_{y}} \\
a=3,16\end{array}$ & $\begin{array}{c}\frac{\tau_{F E}}{\tau_{y}} \\
a=2,16\end{array}$ & $\frac{\tau_{n, S B}}{\tau_{y}}$ & $\frac{\tau_{n, E C}}{\tau_{y}}$ & $\frac{\tau_{n, B A}}{\tau_{y}}$ & $\frac{\tau_{n, B A}}{\tau_{I N V}}$ & $\frac{\tau_{n, B A}}{\tau_{F E}}$ \\
\hline 1 & 2 & 3 & 4 & 5 & 6 & 7 & 8 & 9 & 10 & 11 & 12 \\
\hline $500 \times 2$ & & 131.0 & 135.2 & & 0.81 & 0.83 & 0.79 & 0.86 & 0.86 & & 1.06 \\
\hline $500 \times 2.5$ & & 136.7 & 135.2 & & 0.84 & 0.83 & 0.79 & 0.91 & 0.86 & & 1.02 \\
\hline $500 \times 3$ & & 136.6 & 134.9 & & 0.84 & 0.83 & 0.79 & 0.95 & 0.86 & & 1.02 \\
\hline $1000 \times 2$ & 142.5 & 139.1 & 139.0 & 0.81 & 0.86 & 0.86 & 0.79 & 0.83 & 0.86 & 1.06 & 1.00 \\
\hline $1000 \times 2.5$ & 148.0 & 139.0 & 139.2 & 0.84 & 0.86 & 0.86 & 0.79 & 0.88 & 0.86 & 1.03 & 1.00 \\
\hline $1000 \times 3$ & 138.3 & 140.6 & 139.1 & 0.81 & 0.87 & 0.86 & 0.79 & 0.93 & 0.86 & 1.06 & 0.99 \\
\hline $1250 \times 2$ & & 139.1 & 138.9 & & 0.86 & 0.86 & 0.79 & 0.82 & 0.85 & & 0.99 \\
\hline $1250 \times 2.5$ & & 139.0 & 138.9 & & 0.86 & 0.86 & 0.79 & 0.88 & 0.85 & & 1.00 \\
\hline $1250 \times 3$ & & 138.9 & 138.8 & & 0.86 & 0.86 & 0.79 & 0.92 & 0.86 & & 1.00 \\
\hline $1500 \times 2$ & 124.3 & 139.9 & 136.9 & 0.81 & 0.86 & 0.84 & 0.79 & 0.82 & 0.84 & 1.04 & 0.98 \\
\hline $1500 \times 2.5$ & & 139.1 & 135.2 & & 0.86 & 0.83 & 0.79 & 0.87 & 0.85 & & 0.99 \\
\hline $1500 \times 3$ & & 134.2 & 135.7 & & 0.83 & 0.84 & 0.79 & 0.92 & 0.85 & & 1.02 \\
\hline AVG. & & & & 0.82 & 0.85 & 0.85 & 0.79 & 0.88 & 0.85 & 1.05 & 1.01 \\
\hline
\end{tabular}

At $\lambda<0.6$, in the elastic-plastic and plastic zones, the solution in accordance with EC3 [1] is not conservative or overestimated.

In the group of design shear buckling resistances, the solution proposed by the author in the form of Eqs. (22) and (23), based on the determination of interactive buckling resistance from Eq. (21), produces the results that are closest to experimental and FEM data. For the solution of concern, the range of congruence with experimental and FEM results is 0.99-1.09 for girders with semirigid end stiffener, and 1.01-1.05 for girders with rigid end stiffener.

The formulas developed for the estimation of interactive shear buckling resistance (Eq. 21) and design shear buckling resistance (Eqs. (22) and (23)) can be applied, in practice, to girder fabrication scope from $h_{w}=500$ to $h_{w}=1500 \mathrm{~mm}$.

Normalized shear buckling resistance was presented as a function of interactive slenderness $\left(\lambda_{I, 6}\right)$ for the experimental investigations $\tau_{(I N V)} / \tau_{y}$ and FE analysis $\tau_{(F E M)} / \tau_{y}$, and for the for the solution developed by the author $\tau_{n, B A(22)} / \tau_{y}, \tau_{n, B A(23)} / \tau_{y}$, and also for the Sause and Braxtan model [6] $\left(\tau_{n, S B} / \tau_{y}\right)$. For the solution adopted in EC3 [1] $\left(\tau_{n, E C} / \tau_{y}\right)$, normalized shear buckling resistance was presented as a function of slenderness $(\lambda)$. The graphs are shown in Fig. 17. It should be noted that the range of interactive slenderness $\lambda_{I, 6}$ determined for girders with sine wave corrugated web $h_{w}=500-1500$ is $0.35-0.99$ (semirigid 


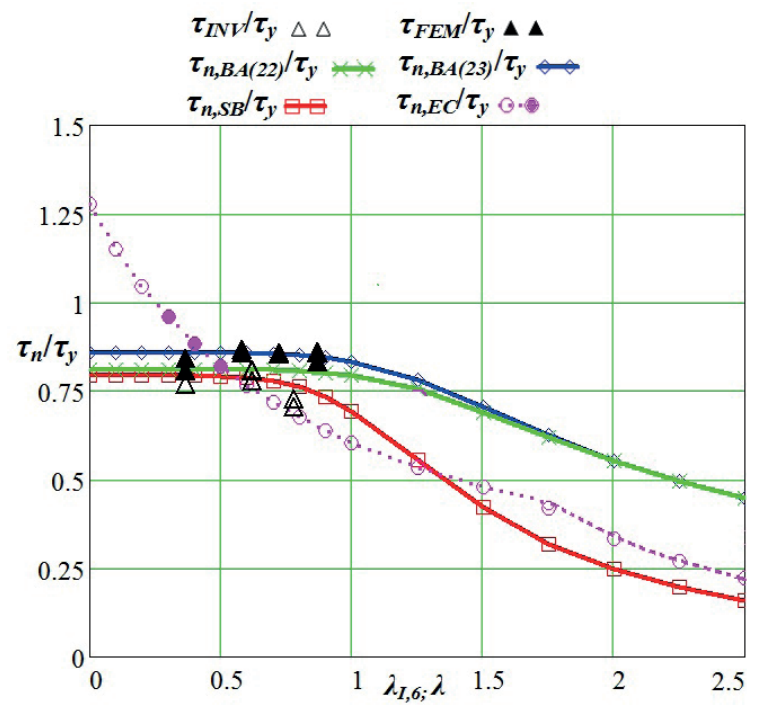

Fig. 17 Normalized shear buckling resistance vs slenderness

end stiffener) and 0.35-0.92 (rigid end stiffener). Additionally, slenderness computed acc. EC3 [1] varies $0.35-0.51$. As a result, design shear buckling resistance of the web determined acc. EC3 [1] is overestimated by up to $16 \%$. However, in the Moon's solution [12], at $\lambda<0.6$, shear buckling resistance in trapezoidally corrugated webs can reach the yield strength of the material. Experimental and FEM results demonstrate that girders with sine wave corrugated web instability are below the shear yield strength.

\section{Conclusions}

Corrugated web girders are internally statically indeterminate structures. The dimensions of the web, flanges and end stiffeners interact to affect the web shear resistance, and thus design shear buckling resistance.

Failure of corrugated web girders is related to the occurrence of tension line along the yield stresses zones in the corrugated web. Yield stresses zones are irreversible in character and they significantly contribute to the limitation of the girder resistance.

In sine wave corrugated web girders, two failure modes of the web actually occur, namely local and interactive one. Physically, the web failure mode is affected by the radius of the web wave, the wave length and the web height.

The web failure occurs abruptly. The process of instability of the corrugated web starts with the local instability of the sinusoidal panel. The occurrence of the tension line is followed by the development of yield stresses zone (local instability $L$ ), or tension field leads to the formation of yield stresses zone related to the jumping of the neighbouring waves of the web (interactive instability $-I$ ). In webs of girders that are $h_{w}=$ $500 \mathrm{~mm}$ in height, local instability is observed. In girders with greater web heights, interactive instability is found.

Interactive and design buckling resistances are clearly affected by flexural stiffness of end stiffeners. In girders, the end stiffeners of which were additionally reinforced with tee bars, the web buckling resistance increased (girders of group
"2"). Rigidity of end stiffeners can be increased by having tee bars bolted to them, as shown in Fig. $2 \mathrm{f}$.

An increase in the cross section of end stiffeners in corrugated web girders leads to a wider range of elastic deformation $0-P_{1}\left(P_{e B}\right)$ of the web, which contributes to an increase in its buckling resistance. On the basis of the laboratory tests, after the random effect of yield strength was eliminated, it was found that design buckling resistance increased up to $11 \%$. As for FEM analysis, an increase in the design buckling resistance fluctuated around $6 \%$ (see Tables 5 and 6 ).

Design buckling resistance $\tau_{n}$ is also affected by cross-sections of flanges. The failure of the web and the occurrence of the tension line leads to a reduction in the resistance of flanges. At the present state of research into instability loss of sine wave webs of corrugated girders, it should be recommended to use end stiffeners, reinforced with, e.g., tee bars shown in Fig. 2, and also to increase flexural stiffness of flanges. In order to equalize flexural and shear resistance of corrugated web girders, it should be postulated that tension diagonal braces are employed. They need to be used in the girder near-support zones $[28,29]$, in which the shear load is greater than the web shear resistance.

Based on laboratory tests and FEM analysis, a solution was proposed for the estimation of design shear buckling resistance of girders with semirigid (Eq. (22)) and rigid (Eq. (23)) end stiffener. The solution relies on determining the interactive buckling resistance from Eq. (24). The range of congruence between the proposed solution and experimental and FEM results was 0.99-1.09 for girders with semirigid end stiffener, and 1.01-1.05 for girders with rigid end stiffener.

The solution put forward in this study is better suited to represent design shear buckling resistance than currently used EC3 [1] formulas that overestimate the results by up to $16 \%$. In contrast, the solution by Sause and Braxtan [6] that uses wave shape approximation underestimates the value of design shear buckling resistance by about $4 \%$. Additionally, neither of the solutions accounts for the advantageous effect of end stiffeners, resulting in an increase in design shear buckling resistance.

\section{Acknowledgements}

The research is financed by National Science Centre based on grant No. N N506 072538.

\section{References}

[1] Eurocode 3. "Design of steel structures. Part 1-5: Plated structural elements". EN 1993-1-5. 2008. http://www.phd.eng.br/wp-content/ uploads/2015/12/en.1993.1.5.2006.pdf

[2] Hamilton, R. W. "Behavior of welded girder with corrugated webs". Ph.D. thesis. University of Maine. 1993.

[3] Elgaaly, M., Hamilton, R. W., Seshadri, A. "Shear strength of beams with corrugated webs". Journal Structural Engineering, 122(4), pp. 390-398. 1996.

https://doi.org/10.1061/(ASCE)0733-9445(1996)122:4(390) 
[4] Driver, R. G., Abbas, H. H., Sause, R. "Shear behavior of corrugated web bridge girders". Journal of Structural Engineering, 132(2), pp. 195-203. 2006.

https://doi.org/10.1061/(ASCE)0733-9445(2006)132:2(195)

[5] Sayed-Ahmed, E. Y. "Behavior of steel and (or) composite girders with corrugated steel webs". Canadian Journal Civil Engineering, 28(4), pp. 656-672. 2001.

https://doi.org/10.1139/101-027

[6] Sause, R., Braxtan, T. N. "Shear strength of trapezoidal corrugated steel webs". Journal of Constructional Steel Research, 67(2), pp. 223236. 2011

https://doi.org/10.1016/j.jcsr.2010.08.004

[7] Yi, J., Gil, H., Youm, K., Lee, H. "Interactive shear buckling behavior of trapezoidally corrugated steel webs". EngineeringStructures, 30(6), pp. 1659-1666. 2008.

https://doi.org/10.1016/j.engstruct.2007.11.009

[8] Abbas, H. H., Sause, R., Driver, R. G. "Shear strength and stability of high performance steel corrugated web girders". In: Annual conference, Structural Stability Research Council, 2002, Seattle, WA. pp. 361-387. 2002.

[9] El-Metwally, A. S. "Pre-stressed composite girders with corrugated steel webs". Thesis for degree of master, University of Calgary. Calgary, Alberta, Canada. 1998.

[10] Hassanein, M. F., Kharoob, O. F. "Behavior of bridge girders with corrugated webs: (II) Shear strength and design". Engineering Structures 57, pp. 544-553. 2013. https://doi.org/10.1016/j.engstruct.2013.04.015

[11] Shiratani, H., Ikeda, H., Imai, Y., Kano, K. "Flexural shear behavior of composite bridge girder with corrugated steel webs around middle support". Japan Society of Civil Engineering, 2003(724), pp. 49-67. 2003. https://doi.org/10.2208/jscej.2003.724_49

[12] Moon, J., Yi, J., Choi, B. H., Lee, H. E. "Shear strength and design of trapezoidally corrugated steel webs". Journal of Constructional Steel Research, 65(5), pp.1198-205. 2009. https://doi.org/10.1016/j.jcsr.2008.07.018

[13] Eldib, M. E. A.-H. "Shear buckling strength and design of curved corrugated steel webs for bridges". Journal of Constructional Steel Research, 65(12), pp. 2129-2139. 2009. https://doi.org/10.1016/j.jcsr.2009.07.002

[14] Basiński, W., Kowal, Z. "The shear resistance of girders with corrugated web". Inżynieria i Budownictwo, 64(4), pp. 197-200. 2008. (in Polish).

[15] Basiński, W., Kowal, Z. "The influence of the stiffness of end stiffeners on critical shear resistance of corrugated web of girders". Konstrukcje Stalowe, 3, pp. 50-54. 2013. (in Polish).

[16] Basiński, W. "Analysis of oscillatory motion of SIN girders with semirigid joints". Architecture Civil Engineering, Environment, 9(4), pp. 55-65. 2016.

[17] Höglund, T. "Shear buckling resistance of steel and aluminium plate girders". Thin-Walled Structures, 29(1-4), pp. 13-30. 1997. https://doi.org/10.1016/S0263-8231(97)00012-8

[18] "Profiles of corrugated web of SIN girders. Principles of dimensioning". Cracow University of Technology. Cracow. 2002. (in Polish).

[19] The research project N N506 072538 "Shaping frameworks girder on the corrugated web joined by end plates". Silesian University of Technology. 2013. (in Polish).

[20] Easley J. T., McFarland D. E. "Buckling of light - gage corrugated metal shear diagrams". Journal Structural Division, 95, pp. 1497-1516. 1969.

[21] Easley, J. T. "Buckling formulas for corrugated metal shear diaphragms". Journal Structural Division, 101(7), pp. 1403-1417. 1975.

[22] Seydel, E. "Beitrag zur Frage des Ausbeulens von versteiften Platten bei Schubbeanspruchung". Jahrbuch 1930 der Deutschen Versuchsanstalt fur Lufffahrt, pp. 235-254. 1930.
[23] Timoshenko, S. P., Gere, J. M. "Theory of elasticstability". Arkady. Warszawa. 1961.

[24] EN 10002-1. "Metallic materials - Tensile testing - Part 1: Method of test at ambient temperature". 2001.

[25] This research was supported in part by PL-GRID infrastructure, and also by the WIND grant.

[26] Kuchta K. "Resistance and stiffness of plate girders with corrugated web". Ph.D. thesis. Technical University of Cracow. 2004. (in Polish).

[27] Memon B. A. "Arc-length technique for nonlinear finite element analysis". Journal of Zhejiang University SCIENCE, 5 (5) pp. 618-628. 2004. DOI. org/10.1631/jzus.2004.0618

[28] Basiński W., Kowal Z. "Investigations into the resistance of sin girders reinforced with tensioned diagonal braces". Architecture Civil Engineering, Environment. Vol. 10 No 1, pp. 53-64. 2017.

[29] Basiński W., Kowal Z. "FEM analysis of corrugated web girders reinforced with tensioned diagonal braces". Architecture Civil Engineering, Environment. Vol. 10 No 1, pp. 65-78. 2017. 